\title{
Fetoinfantile losses in the north-west region of Russia
}

\author{
D.O. Ivanov', V.K. Iurev², K.G. Shevtsova ${ }^{3}$, K.E. Moiseeva ${ }^{4}$, E.N. Berezkina ${ }^{3}$
}

\begin{abstract}
In order to assess fetoinfantile losses in the North-West of Russia, the official and operational data of the Federal State Statistics Service and the Central Research Institute of Health Organization and Informatization of the Ministry of Health of the Russian Federation for 2010-2016 were studied. It is established that the indicator of fetoinfantile losses in the North-West region is much lower than fetoinfantile losses in the whole Russia. The evaluation of the dynamic coefficient of fetoinfantile losses showed a decrease for the years 2012-2016, as in Russia in general and in the North-West region. The structure of fetoinfantile losses in 2016 in the Russian Federation was significantly dominated by the share of infant mortality, and in the North-West Federal district - stillbirth. In the structure of fetoinfantile losses attributable to the period of infant mortality, the largest share accounted for mortality in the early neonatal period. Reduction of fetoinfantile losses due to infant mortality has been achieved mainly due to early neonatal mortality. Level of fetoinfantile losses attributable to the period of early neonatal deaths had a direct correlation with mortality level of children with a body weight of 1000 grams or more in the departments of pathology of newborns. The frequency of deaths in children weighing 1000 grams or more in the neonatal pathology departments of the North-West Federal district is significantly higher than in the whole Russia. The survival rate of children with extremely low birth weight from the total number of children born with a body weight of 500-999 grams in the North-Western region exceeded the figure for the whole Russia by $48.32 \%$.
\end{abstract}

Keywords: fetoinfantile losses, infant mortality, neonatal mortality, stillbirth, mortality rate, neonatal pathology department

\section{INTRODUCTION}

In Russia, the concept of "demographic policy" goes far beyond the usual population statistics $(1,2)$. The Russian Federation, being the largest state in the world by the size of its territory, has a rather low number and density of the population living on it. In such an unfavorable situation, there is a real threat of weakening the political, economic and defense potential of the country, which becomes a matter of state security (3).

The problem of preserving the life and strengthening the health of children is a top priority of state policy and is considered as a guarantee of success in the social and economic development of the state (4-7). For the full functioning of society it is extremely important to preserve the life of every child (8-10). A significant number of scientific studies, both of domestic and foreign authors are devoted to the study of the losses of viable children (11-15). Until 1997, in the medical literature, as a rule, infant and perinatal mortality rates were considered separately, which made it impossible to assess objectively the situation (16). In the history of statistical accounting of these indicators, there were cases of distortion by "transfer" of dead children from one group to another. Unfortunately, at the present stage this trend continues. Thus, a comparison of individual components of perinatal mortality demonstrates the presence of logical inconsistencies. Comparison of the total number of stillborn children and children with a body weight of 1000 grams or more, whose death occurred before the birth, in 11 of 85 subjects of the Russian Federation, showed a negative difference, i.e. the number of children who died antenatally exceeded the total number of stillborn children accounted

\footnotetext{
Doctor of Medical Sciences (Advanced Doctor), Rector of St. Petersburg State Pediatric Medical University, Chief Neonatologist of the Ministry of Health of the Russian Federation, Russia.

2 Head of the Department of Public Health and Health Care, St. Petersburg State Pediatric Medical University, Russia.

3 Postgraduate at the Department of Public Health and Health Care, St. Petersburg State Pediatric Medical University, Russia.

${ }^{4}$ Associate Professor at the Department of Public Health and Health Care, St Petersburg State Pediatric Medical University, Russia.
}

\section{Correspondence: D.O. Ivanov}

Doctor of Medical Sciences (Advanced Doctor), Rector of St. Petersburg State Pediatric Medical University, Chief Neonatologist of the Ministry of Health of the Russian Federation, Russia.

Received: 5 Sep 2018, Accepted: 27 Nov 2018

(C) 2019 by the authors; licensee Modestum Ltd., UK. This article is an open access article distributed under the terms and conditions of the Creative Commons Attribution License (http://creativecommons.org/licenses/by/4.0/). 
for in the perinatal mortality. The total amount of logical discrepancy for 2016 was 277 dead children (or $23 \%$ of the number of stillbirths in the relevant regions of the Russian Federation) (17).

With the aim of eliminating these drawbacks the indicator of fetoinfantile losses was proposed $(18,19)$. The indicator of fetoinfantile losses was recommended for use by the World Health Organization and includes stillbirths and deaths of infants in the first year of life (20-22). This indicator most fully characterizes the work of the system of protection of motherhood and childhood at all its stages and makes it possible to implement management decisions to preserve not only every held, but also every potential human life (23). Fetoinfantile losses have a significant impact on basic sociodemographic processes (24).

The aim of the study is to evaluate the features of fetoinfantile losses in the North-West of the Russian Federation.

\section{MATERIALS AND METHODS}

The present study was conducted in the North-West region of Russia, which includes the territory of two republics, seven regions, one autonomous district and one city of Federal significance. The total population of the Russian regions is 13 million 512 thousand people.

The official statistical reports and publications of the Federal State Statistics Service for 2010-2016, collections of "Main indicators of mother and child health, activities of the child protection and maternity service in the Russian Federation" of Central Research Institute of Organization and Informatization of Health Care of the Ministry of Health of the Russian Federation for 2013-2016 were analyzed.

Statistical processing of the results and analysis of the data was carried out using computer programs Microsoft Office Excel 2007 and software package for statistical analysis developed by StatSoft - Statistica 7.0. Level of significance was set as $p \leq 0.05$. Spearman's correlation coefficient was used to analyze the relationship between the variables.

\section{RESEARCH RESULTS AND THEIR DISCUSSION}

A comparative assessment of the coefficient of fetoinfantile losses in the North-Western Federal district showed that in 2016 it was $10.78 \%$ o ( $m \pm 0.24$ ), which is significantly lower than the same indicator for the whole Russia- 11.75 ( $m \pm$ 0.08). At the same time, the variability interval between the subjects of the Russian Federation within the region was 6.5 $\%$. Significantly high relative to the average value in the region it was in Pskov region $13.85 \%$ o $(m \pm 0.08)$, low $-8.05 \%$ o $(m \pm 0.96)$ in Murmansk region $(p \leq 0.05)$.

The study of the dynamics of fetoinfantile losses of the North-Western Federal district for the period $2010-2016$, revealed their significant increase in 2012. In 2011, the ratio of fetoinfantile losses did not significantly differ from the 2010 level and was equal to 10.01\%o ( $m \pm 0.25)$. In 2012, its value increased sharply and was determined at the level of $12.97 \%$ o $(m \pm 0.28)$, i.e. the growth rate was $29.7 \%$, which corresponds to the trend in this period in Russia in connection with the transition of the Russian Federation to a new, comparable with the international system of birth registration. However, since 2013 the dynamics of the studied indicator has been characterized by a steady decline. In 2013, it decreased by 3.5\%; in 2014 - by 9.8\%; in 2015 - by $4.74 \%$ and in 2016 its value differed insignificantly from the 2010 indicator: $2010-10.31 \%$ o $(m \pm 0.26) ; 2016-10.78 \%$ ( $m \pm 0.24)$ ( $p \geq 0.05$ ). In the whole of Russia in 2012-2016 fetoinfantile losses steadily dropped in 2012 by $20.93 \%$, and in 2016 the figure is not only back to the level of 2010, but was considerably lower: in 2010 - of 12.07\%o ( $m \pm 0.08) ; 2016$ and 11.75\%o $(m \pm 0.08),(p \leq 0.05)$.

The study of the structure of fetoinfantile losses of the Russian Federation showed that it was significantly dominated by the share of losses of viable children, coinciding with the period of infant mortality. In 2016, the infant mortality rate was $6.02 \%$ o $(m \pm 0.06)$, which is $51.22 \%$ of all fetoinfantile losses and significantly exceeds the proportion of losses associated with stillbirth $-5.73 \%$ o $(m \pm 0.06)$, or $48.78 \%(p \leq 0.05)$.

Evaluation of the structure of fetoinfantile losses of the North-Western Federal district showed differences from the situation typical for the whole Russian Federation. It varies, both in terms of stillbirths and in terms of infant mortality. In the region, the share of losses associated with stillbirth is $55.71 \%(\mathrm{~m} \pm 0.55)$, which is higher than in Russia by $6.93 \%$ ( $p \leq$ 0.05 ), while the share of infant mortality is lower by $6.93 \%$ (in the Russian Federation $-51.22 \%(\mathrm{~m} \pm 0.15)$; in the NorthWest Federal district $-44.29 \%(\mathrm{~m} \pm 0.49), p \leq 0.05)$.

Nevertheless, in two subjects of the Russian Federation of the studied region, as well as in Russia as a whole, the share of stillbirths is less than $50 \%$. These include: the Republic of Karelia $-39.77 \%$ and Pskov region $-46.0 \%$. In 7 regions of the region the share of stillbirths in the structure of fetoinfantile losses varies from $50 \%$ to $56 \%$ : the Republic of Komi - 50,41\%; Kaliningrad region - 50.89\%; Murmansk and Vologda regions - 52.17\% and 52.51\% respectively; Arkhangelsk 
Table 1: Comparative characteristics of the structure of fetoinfantile losses in 2016

\begin{tabular}{|c|c|c|c|c|c|}
\hline \multirow{3}{*}{ Study area } & \multicolumn{3}{|c|}{ Fetoinfantile losses } & \multicolumn{2}{|c|}{ Share of infantile losses in part: } \\
\hline & \multirow{2}{*}{$\begin{array}{l}\text { Overall coefficient } \\
\text { (in \%) }\end{array}$} & \multicolumn{2}{|c|}{ Including the part } & \multirow{2}{*}{ Infant mortality (in \%) } & \multirow{2}{*}{ Stillbirth (in \%) } \\
\hline & & Infant mortality (in \%) & Stillbirth (in \%) & & \\
\hline Russian Federation & 11.75 & 6.02 & 5.73 & 51.22 & 48.78 \\
\hline North-Western Federal district & 10.78 & 4.78 & 6.01 & 44.29 & 55.71 \\
\hline Republic of Karelia & 11.64 & 7.01 & 4.63 & 60.23 & 39.77 \\
\hline Republic of Komi & 10.90 & 5.41 & 5.50 & 49.59 & 50.41 \\
\hline Arkhangelsk region & 12.48 & 5.71 & 6.77 & 45.76 & 54.24 \\
\hline Vologda region & 13.83 & 6.57 & 7.26 & 47.49 & 52.51 \\
\hline Kaliningrad rergion & 9.15 & 4.49 & 4.65 & 49.11 & 50.89 \\
\hline Leningrad region & 10.75 & 4.25 & 6.50 & 39.55 & 60.45 \\
\hline Murmansk region & 8.06 & 3.85 & 4.20 & 47.83 & 52.17 \\
\hline Novgorod region & 9.94 & 4.42 & 5.52 & 44.44 & 55.56 \\
\hline Pskov region & 13.86 & 7.48 & 6.37 & 54.00 & 46.00 \\
\hline Saint-Petersburg & 10.07 & 3.92 & 6.15 & 38.94 & 61.06 \\
\hline
\end{tabular}

region (taking into account autonomy) $-54,24 \%$; Novgorod region $-55,56 \%$. The most significant shift towards stillbirths in the structure of fetoinfantile losses is observed in St. Petersburg and the Leningrad region, where the share of children born dead accounts for $61.06 \%$ and $60.45 \%$, respectively. Comparative characteristics of the structure of infantile losses in 2016 are presented in Table 1.

Analysis of the dynamics of fetoinfantile losses within the region, taking into account the structural gradation, showed that in terms of infant mortality, the decline in the indicator relative to 2012 was achieved by all subjects of the Russian Federation of the North-West region. At the same time, a significant difference is observed in Novgorod, Murmansk and Leningrad regions $(p \leq 0.05)$. However, in Murmansk and Leningrad regions, a significant reduction in infant mortality was achieved against the background of an increase in the rate of stillbirth by $2.61 \%$ and $9.83 \%$, respectively, which is not typical for the rest of the subjects of the Russian Federation of the studied region, where the decrease in fetoinfantile losses in terms of infant mortality is accompanied by a slight but steady decrease in the level of stillbirth.

In addition, the analysis found that until 2012 in the structure of fetoinfantile losses in the region, as well as in the whole Russia, the share associated with infant mortality prevails; after 2012 - the share associated with stillbirth. The exception in 2016 is only Pskov region and the Republic of Karelia.

In the structure of stillbirths in 2016 both in Russia and in the North-West Federal district, the proportion of deaths occurring before the onset of generic activity significantly prevailed $-89.80 \%(\mathrm{~m} \pm 0.29)$ and $90.9 \%(\mathrm{~m} \pm 0.93)$, respectively. The highest level of antenatal death relative to the regional indicator was found in Vologda region $-6.50 \%$ o $(m \pm 0.64) p \geq 0.05$, the lowest - in Murmansk region - 3.50\%o $(m \pm 0.64) p \leq 0.05$.

In the structure of fetoinfantile losses, a significant impact on infant mortality provides an indicator of infant mortality attributable to early neonatal period. The direct relationship of these indicators is determined by the correlation coefficient equal to 0.64 , the significance level of which $p=0.001$.

Analysis of the dynamics of early neonatal mortality in the structure of infant mortality showed that its reduction is largely due to the reduction of infant losses of the early neonatal period. So the level of infant mortality in the early neonatal period has decreased from 2012 by 26.85\% (2.56\%o ( $m \pm 0.12)$ in 2012; 1.87\%o ( $m \pm 0.10)$ in $2016 p \leq 0.05)$, while the decline in late neonatal and post-neonatal mortality accounted for only $17.45 \%(3.51 \%$ o $(m \pm 0.14)$ in 2012 ; $2.91 \%$ o $(m \pm 0.18)$ in $2016 p \leq 0.05)$.

The statistical analysis showed that the level of fetoinfantile losses attributable to the period of early neonatal mortality, and infant mortality in general, has a direct correlation with the level of mortality of children weighing 1,000 grams or more (correlation coefficient $=0.36 ; p \leq 0.05$ ).

Every year, about $8 \%$ of newborns with a body weight of 1000 grams or more are subject to transfer to the Department of pathology of newborns. In 2012, the frequency of such cases in the whole Russia was $77.15 \%$ o $(m \pm 0.19)$. In the NorthWestern Federal district, this figure was significantly different from the all-Russian - here for every thousand of live-born children 92 newborns came to the Pathology Department $(91.88 \% \pm 0.71)$. In 2016, the analyzed indicator for the whole Russia increased by $5.61 \%$ compared to 2012 , while in the North-West Federal district there was a steady decline. By 2016, the indicator decreased by $13.91 \%$ and amounted to $79.11 \%$ ( $m \pm 0.64)$, against 91.88 in 2012 .

However, the frequency of deaths among children weighing 1000 grams or more in the North-West Federal district is higher than in the whole Russia by 10\%. In Russia, this figure in 2016 amounted to $9.62 \%$, which is $49.38 \%$ lower than in 2012 , when its value was equal to $19.02 \%$ o $(p \leq 0.05)$ in the North-Western Federal district, the death rate for the 
analyzed period decreased slightly: $2012-12.77 \%$ o $(m \pm 0.9) ; 2016-10.61 \%$ o $(m \pm 0.93)(p \geq 0.05)$. At the same time, the highest value of the indicator of negative outcomes in the Departments of Pathology of Newborns, among children weighing 1000 grams or more, in 2016 was noted in St. Petersburg, where against the background of the frequency of admission of newborns to the Pathology Department is $15 \%$ lower than in Russia, the death rate was higher by $129.5 \%$. So, in Russia from thousands of born alive children 82 newborns ( $81.48 \% \circ \mathrm{m} \pm 0.19)$ came to the Pathology Department, of these, in 10 babies $(9.62 \%$ o \pm 0.25 ) disease ended in death, while in St. Petersburg, 70 out of 1000 live-born children were hospitalized in pathology departments, and the fatal outcome was recorded in 22 cases per thousand treated in these departments. In other subjects of the Russian Federation of the North-west region the studied indicator slightly differed from the all-Russian one.

The present study found that the number of children born with extremely low birth weight for the period 2012-2016 in the whole Russia, and the North-West Federal district did not change significantly. Their share in the total number of children born was about $0.4 \%$ annually.

The estimation of the death rate in children with extremely low birth weight during the analyzed period in Russia decreased significantly. In 2012, out of 100 children admitted to the Neonatal Pathology Department, 28 died (27.66 m \pm 0.8 ), in $2016-20$ (20.37 $\mathrm{m} \pm 0.71)$. The decrease was $26.36 \%(p \leq 0.05)$. In the North-Western Federal district, the number of children admitted to the Department of Pathology of Newborns weighing 500-999 grams had a negative trend: in 2012, the Pathology Department received 455 children, 2016 - 387 (2012 - 2.8\%o m \pm 0.13 per 1000 born children; $2016-2.3 \% \circ \mathrm{m} \pm 0.12 ; p \leq 0.05$ ), while the frequency of deaths increased by $29.74 \%$ and amounted to 24.81 cases for every 100 children admitted to the Department of Pathology, which is higher than the all-Russian indicator by $21.80 \%$.

Along with the mortality of children weighing 500-999 grams in the neonatal pathology departments, we studied the overall survival of children in this category relative to the number of children born with the appropriate body weight.

The survival rate of newborns in this group depends on gestational age and ranges from 6 at 22 weeks of gestational age to $92 \%$ at 28 weeks of gestational age. Infants with birth weight less than 500 grams and gestational age less than 23 weeks rarely survive.

According to the results of the analysis, the survival rate of children with extremely low birth weight in Russia in 2016 was 39 successfully treated newborns per 100 children with appropriate birth weight. The highest indicator in the Russian Federation was in St. Petersburg. It was more than twice as high as the national average (or $124.27 \%$ higher $(p \leq 0.05)$ ) and accounted for 87 surviving children for every 100 extremely low birth weight babies. The survival rate in the NorthWestern Federal district as a whole was quite high in comparison with the Russian average. In 2016, it was 58 newborns successfully treated in the Pathology Department for every 100 children with extremely low body weight, which exceeded the figure for the whole Russia by $48.32 \%(p \leq 0.05)$.

In addition, the specific weight of infants with extremely low body weight transferred to pathology departments at the age of 0-6 days was assessed, which revealed that this figure is significantly higher than the average Russian: in St. Petersburg it is 2 times higher, and in the whole North-West Federal district - 1.3 times.

\section{CONCLUSIONS}

1. The coefficient of fetoinfantile losses in the North-Western region is much lower than the indicator of fetoinfantile losses in the whole Russia. The dynamics of the coefficient fetoinfantile losses showed a significant decline over the period 2012-2016.

2. The structure of fetoinfantile losses in 2016 in the Russian Federation was significantly dominated by the share of infant mortality, and in the North-West Federal district - the share associated with stillbirth. The most significant shift towards stillbirth is observed in St. Petersburg and Leningrad region.

3. In the structure of stillbirths in 2016 both in Russia and in the North-West Federal district the proportion of deaths that occurred before the beginning of generic activity significantly prevailed. In the structure of fetoinfantile losses attributable to the period of infant mortality, the largest share falls in the early neonatal period. A decline of part of fetoinfantile losses by $27 \%$ attributable to the period of infant mortality from 2012 is mainly due to early neonatal mortality.

4. The frequency of deaths in the pathology departments of newborns with a body weight of 1000 grams or more, as well as with extremely low body weight in the North-Western Federal district in 2016 is higher than in the whole 
Russia. The statistical analysis did not reveal a connection between the level of infant mortality and the frequency of deaths in children born with extremely low birth weight, which indicates the rapid development of technologies of nursing children with extremely low body weight, as well as the effective use of modern technologies of intensive care. Analysis of the frequency of deaths among children with extremely low body weight in Russia and the North-West Federal district, found that the mortality of newborns weighing up to $1000 \mathrm{grams}$, is a factor to be improved in the perinatal service of the studied region.

5. The survival rate of children with extremely low body weight from the total number of children born with a body weight of 500-999 grams in the North-West Federal district exceeds the figure for the whole Russia by $48.32 \%$, and in St. Petersburg - by $124 \%$ in the whole Russia.

6. The proportion of newborns with extremely low body weight transferred to pathology departments at the age of 0-6 days is significantly higher than the average Russian level, which gives reason to believe that there is the presence in the studied region of more effective primary resuscitation of newborns in the delivery room, and also indicates a higher level of organization of transportation of newborns to higher-level medical institutions.

\section{REFERENCES}

1. Medik VA, lurev VK. Public health and health care. 2-e is., correc. and suppl. M.: GEOTAR-Media 2016;608.

2. Iurev VK, Moiseeva KE, Gluschenko VA, Kharbediya ShD. Guide to practical training in the study of morbidity of population. St. Petersburg: Sotis-Med 2018;587.

3. Kharbediya ShD. Statistical accounting and standardization in health care. Saint Petersburg: Sotis-Med 2018;228.

4. Ivanov DO. Guide to Perinatology. SPb.: Informnavigator 2015;1216.

5. Ivanov DO, Shevtsova KG. Analysis of selected statistical indicators of the North-Western Federal district in the aspect of infant mortality and stillbirth. Pediatrician. 2018;9(2):16-21. https://doi.org/10.17816/PED925-15

6. Surkov DN, Ivanov DO, Mavropulo TK, Petrenko YuV. Morbidity and mortality of neonates born in gestational age 22-27 weeks. Children's medicine of the North-West. 2012;3(3):14-7.

7. Sakharova ES, Keshishyan ES. Principles of assistance to premature children in the post-neonatal period. Russian journal of Perinatology and Pediatrics. 2014;59(1):40-5.

8. Nove A, Matthews Z, Neal S, Camacho AV. Maternal mortality in adolescents compared with women of other ages: evidence from 144 countries. The Lancet Global Health. 2014;2:155-64. https://doi.org/10.1016/S2214109X(13)70179-7

9. Stephens BE, Vohr BR. Neurodevelopmental Outcome of the Premature Infant. Pediatr Clin North Am 2009;56(3):631-46. https://doi.org/10.1016/j.pcl.2009.03.005

10. World Health Organization. Levels and trends in child mortality. Geneva, 2012;32.

11. Perlman JM. Neurology: neonatology questions and controversies. Saunders, Elsevier 2008;288.

12. Lau C, Ambalavanan N, Chakraborty H, Wingate SM, Carlo AW. Extremely Low Birth Weight and Infant Mortality Rates in the United States. Pediatrics. 2013;131(5):52-67. https://doi.org/10.1542/peds.2012-2471 PMid:23545381

13. Kusuda S, et al. Morbidity and Mortality of Infants with Very Low Birth Weight in Japan. Center Variation, Pediatrics. 2006;118:1130 -8. https://doi.org/10.1542/peds.2005-2724 PMid:16950943

14. Jacob J, Kamitsuka M, Clark HR, Kelleher SA, Spitzer RA. Etiologies of NICU Deaths. Pediatrics. 2015;135(1):12335. https://doi.org/10.1542/peds.2014-2967 PMid:25489010

15. Lee KS, Mori R, Kusuda S, Fujimura M, Xiang Y, Shah SP. Comparison of Mortality and Morbidity of Very Low Birth Weight Infants Between Canada and Japan. Pediatrics. 2012;130(4):12-9.

16. Baranov AA, Albitskiy VYu. Mortality of children population in Russia (tendencies, causes, and ways to reduce). M.: Union of pediatricians of Russia 2009;392.

17. Polikarpov AV, Aleksandrova GA, Golubev NA, Tyurina EM, etc. Main indicators of the health of the mother and child, the activities of the service for childhood and obstetrics in the Russian Federation. M., FRIHOIMHRF 2018;170. Retrieved from http://mednet.ru/ru/statistika/materinstvo-i-detstvo.html

18. Blondel B, Breart G. Mortalite foetoinfantile. Evolution, causes et tsd'annalyse. Eneyel. Med. Chir (Paris-France). Pediatrie; 1990.

19. Wille L, Obladen M. Neugerborgen-Intensivpflege. Gru Richtlinien/Springer-Verlag-Berlin; 1984:377-87. https://doi.org/10.1007/978-3-662-08940-8 
20. Sakharova ES, Keshishyan ES. Principles of assistance to premature children in the post-neonatal period. Russian journal of Perinatology and Pediatrics. 2014;59(1):40-5.

21. Baybarina EN, Filippov OS, Guseva EV. Modernization of maternity and childhood protection service in the Russian Federation: results and prospects. Obstetrics and gynecology 2013;12:4-9.

22. Chuvakova TK, Karin BT. Introduction of effective technologies in the practice of organizations of maternity and childhood in Kazakhstan. Medicine and health organization. 2017;4(2):19-24.

23. Egan $M$, Petticrew $M$, Thomas $S$, et al. Risk factors in home and community settings and their associations with population health. Public Health. 2014;8:227.

24. Ivanova LA, Titkova EV. Clinical features of newborns in patients with perinatal losses. Pediatrician. 2018;9(2):1621.

$\diamond \diamond \diamond \diamond \diamond \diamond \diamond$

http://www.ejgm.co.uk 